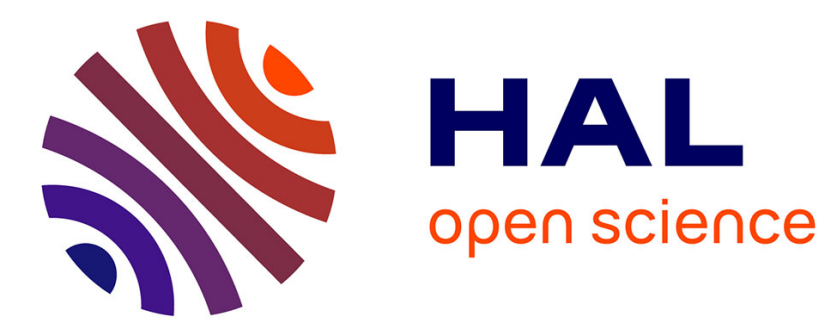

\title{
State and Unknown Inputs Estimations for Multi-Models Descriptor Systems
}

Chokri Mechmeche, Habib Hamdi, Mickael Rodrigues, Naceur Benhadj Braiek

\section{To cite this version:}

Chokri Mechmeche, Habib Hamdi, Mickael Rodrigues, Naceur Benhadj Braiek. State and Unknown Inputs Estimations for Multi-Models Descriptor Systems. American Journal of Computational and Applied Mathematics, 2012, 2 (3), p. 86-93, DOI: 10.5923/j.ajcam.20120203.04. hal-00741162

\section{HAL Id: hal-00741162 \\ https://hal.science/hal-00741162}

Submitted on 11 Oct 2012

HAL is a multi-disciplinary open access archive for the deposit and dissemination of scientific research documents, whether they are published or not. The documents may come from teaching and research institutions in France or abroad, or from public or private research centers.
L'archive ouverte pluridisciplinaire HAL, est destinée au dépôt et à la diffusion de documents scientifiques de niveau recherche, publiés ou non, émanant des établissements d'enseignement et de recherche français ou étrangers, des laboratoires publics ou privés. 


\title{
State and Unknown Inputs Estimations for Multi-Models Descriptor Systems
}

\author{
Chokri Mechmeche $^{1}$, Hamdi Habib ${ }^{1, *}$, Mickael Rodrigues ${ }^{2}$, Naceur BenHadjBraiek $^{1}$ \\ ${ }^{1}$ Laboratoire d'Etude et Commande Automatique des Processus (LECAP), Ecole Polytechnique de Tunisie \\ ${ }^{2}$ Laboratoire d'Automatique et de Génie des Procédés (LAGEP), CNRS UMR 5007, Université Lyon 1, France
}

\begin{abstract}
In this note, the problem of states and unknown inputs estimation of nonlinear descriptor system is considered. The methodology is based on the use of Proportional Integral and Unknown Input Observers. The considered nonlinear descriptor system is transformed into an equivalent multi-models form by using the Takagi-Sugeno (T-S) approach. In this paper, the design methods of both proportional integral observers and unknown inputs observers for descriptor multi-models are described in detail. Sufficient conditions of stability analysis and gain matrices determination are performed by resolving a set of Linear Matrices Inequalities (LMIs). The design method offers all the degrees of design freedom, which can be utilized to achieve various desired system specifications and performances and, thus, has great potentials in applications. A numerical example is employed to show the design procedure of these two observers and illustrate the effect of the proposed approach.
\end{abstract}

Keywords Nonlinear Descriptor System, Multi-Model Descriptor System, Proportional Integral and Unknown Input Observer, LMIs

\section{Introduction}

Nonlinear descriptor processes are usually described by analytical models. These models include both dynamic and static relations. Consequently this formalism can model physical constraints or impulsive behavior due to an improper part of the system. Descriptor systems appear in many fields of system design and control such as constrained robots, power systems, hydraulic or electrical networks. For conventional systems, various approaches have been proposed to design observers. The observer classically used, within the framework of linear systems, is known as Luenberger observer or with profit Proportional[7]. In presence of unknown disturbances affecting system[13], the state estimation provided by this type of observer, is considerably degraded. In order to improve the observer design with respect to the disturbances, an ob- server with Proportional Integral gain can be used. Indeed, this observer makes it possible to integrate certain degree of robustness in state estimation thanks to the integral action[3]. Like to ordinary system theory, the problem of designing observer for descriptor linear system has been considered by many authors. Some approaches are lead to the construction of full-order and reduced-order observers[12]. Others

* Corresponding author:

hammmdihabib@yahoo.fr (Hamdi Habib)

Published online at http://journal.sapub.org/ajcam

Copyright (C) 2012 Scientific \& Academic Publishing. All Rights Reserved approaches develop the concept of singular value decompositions and generalized inverse matrix[10] in order to construct the state vector for this class of systems. Some researchers have also introduced the integral term in observer design for descriptor linear systems. Indeed, in[1] and[2], a design approach of Proportional Integral Observer (PIO) for continuous time descriptor linear systems has been proposed. Koenig et al.[6] have investigated the Luenberger full-order and reduced order PIO with unknown inputs. However, few works have been done to design observers for nonlinear descriptor system except for[5]. In a recent work of Kaprielian et al.[17], a state observer based on the linearization technique of nonlinear descriptor systems with application to a physical process has been developed. The design of these algorithms can become very difficult even impossible according to the type and the complexity of the employed model, from where the importance to have a mathematical model of the system where it's at the same time, simple and precise. The multi-models approach is a powerful technique of modeling nonlinear systems which make it possible to get a good compromise between the precision and the complexity of the model[14]. Multi-models are recognized for their capacity to take into account the changes in the operating mode of the system and to reproduce its behavior with precision in a broad operating range. Moreover, they offer mathematical properties which can be profitable during the design of observers. More recently, few results have been generalized to the descriptor multi- models. In[4], a state estimation method for singular multi-models with measurable decision variables affected by unknown inputs has been 
presented. This proposed observer has been applied to fault detection. $\operatorname{In}[8]$ and[9] the problem of fault detection isolation and estimation for LPV polytopic descriptor system has been studied by using unknown inputs observer and proportional integral observer. From these works and others, state estimation as well as unknown inputs is very significant in command or diagnosis of systems. This has motivated us to study these problems for descriptor multi-models by both unknown inputs and PI observers. Thus some new results are proposed in this paper, a comparison study between two types of observers is presented. This comparison wants to underline the differences for the design of such observers and also to compare the estimation performances of them. This discussion wants to lead us which of these two observers are less restrictive for nonlinear descriptor systems described by a multi-models approach.

This paper is organized as follows: in Section 2 the multimodels structure of nonlinear descriptor systems is introduced. In Section 3, we study the structure and the design of the proposed proportional integral and unknown inputs multi-observer. An illustrative example is considered in section 4 .

\section{Multi-models Singular System}

Consider the following nonlinear descriptor system

$$
\left\{\begin{array}{l}
E \dot{x}(t)=F(x(t), u(t), d(t)) \\
y(t)=g(x(t), u(t))
\end{array}\right.
$$

where $\mathrm{x} \in \mathbf{R}^{\mathbf{n}}$ is the singular state vector, $\mathrm{u} \in \mathbf{R}^{\mathbf{p}}$ is the input vector, $\mathrm{d} \in \mathbf{R}^{\mathrm{q}}$ is a constant unknown input vector and $y \in \mathbf{R}^{\mathbf{m}}$ is the output vector. The function $F$ is a continuous and infinitely differentiable nonlinear function and $\mathrm{E}$ is a singular matrix with constant parameters and $\operatorname{rank}(E)=r<n$. The dynamic behavior of this nonlinear system can $b$ e characterized by a coupled Takagi-Sugeno[15] representation composed by several local linear models. So, based on Taylor series expansion of the smooth nonlinear functions around various operating points (xi, ui), the multi-models representation[14] of (1) is:

$$
\left\{\begin{array}{l}
E \dot{x}(t)=\sum_{i=1}^{h} h_{i}(\xi(t))\left(A_{i} x(t)+B_{i} u(t)+R_{i} d(t)+\Delta x_{i}\right) \\
y(t)=C x(t)
\end{array}\right.
$$

$A_{i}, B_{i}$ and $R_{i}$ are the Jacobean matrices relating to the $i^{\text {th }}$ operating point. $\Delta \mathrm{x}_{\mathrm{i}}$ is a vector depends on the $\mathrm{i}^{\text {th }}$ operating point. hi $(\xi(t))$ quantifies the relative contribution of each local model to construct the global model[18]. The weighting function satisfies the property of the convex sum

$$
\left\{\begin{array}{l}
\sum_{\mathrm{i}=1}^{\mathrm{h}} \mathrm{h}_{\mathrm{i}}(\xi(\mathrm{t}))=1 \\
0 \leq \mathrm{h}_{\mathrm{i}}(\xi(\mathrm{t})) \leq 1
\end{array}\right.
$$

The decision variable $\xi(\mathrm{t})$ is supposed to be real-time accessible, depending on the control input, or on the measured state. Then, before giving the main results, let us make the following assumptions.

Assumption A1: The triple matrix $\left(\mathrm{E}, \mathrm{A}_{\mathrm{i}}, \mathrm{C}\right)$ is R-detectable, for all $\mathrm{i}=1, \ldots, \mathrm{h}[12]$, i.e.,

$$
\operatorname{rank}\left[\begin{array}{c}
\mathrm{sE}-\mathrm{A}_{\mathrm{i}} \\
\mathrm{C}
\end{array}\right]=\mathrm{n}, \forall \mathrm{s} \in \varsigma
$$

where $C$ is the complex plane.

Assumption A2: The triple matrix (E, A, C) is Impulse-observable, for all $\mathrm{i}=1, \ldots, \mathrm{h}[12]$, i.e.,

$$
\operatorname{rank}\left[\begin{array}{cc}
\mathrm{E} & \mathrm{A}_{\mathrm{i}} \\
0 & \mathrm{E} \\
0 & \mathrm{C}
\end{array}\right]=\mathrm{n}+\operatorname{rankE}
$$

In the following subsection, a simple method is proposed to design a PIO for descriptor multi-models subjects to disturbances. This method is less restrictive then unknown inputs observer design since no assumption is made on the disturbances matrices Ri.

\section{Proportional Integral (PI) Muti-Observer Structure}

In the deterministic case, the Proportional Integral MultiObserver (PIMO) is characterized by the use of an integral term of the estimation outputs error[11]. The equations which govern the PIMO are as follows:

$$
\left\{\begin{array}{l}
\dot{\mathrm{z}}(\mathrm{t})=\sum_{\mathrm{i}=1}^{\mathrm{h}} \mathrm{h}_{\mathrm{i}}(\xi(\mathrm{t}))\left(\mathrm{N}_{\mathrm{i}} \mathrm{z}(\mathrm{t})+\mathrm{G}_{\mathrm{i}} \mathrm{u}(\mathrm{t})+\mathrm{L}_{\mathrm{i}} \mathrm{y}(\mathrm{t})+\mathrm{H}_{\mathrm{i}} \hat{\mathrm{d}}(\mathrm{t})+\Delta \mathrm{z}_{\mathrm{i}}\right) \\
\hat{\mathrm{x}}(\mathrm{t})=\mathrm{z}(\mathrm{t})+\mathrm{My}(\mathrm{t}) \\
\dot{\hat{\mathrm{d}}}(\mathrm{t})=\sum_{\mathrm{i}=1}^{\mathrm{h}} \mathrm{h}_{\mathrm{i}}(\xi(\mathrm{t})) \Phi_{\mathrm{i}}(\mathrm{y}(\mathrm{t})-\hat{\mathrm{y}}(\mathrm{t}))
\end{array}\right.
$$

where $\hat{x} \in \mathbf{R}^{\mathbf{n}}, \mathrm{z} \in \mathbf{R}^{\mathbf{n}}$ and $\hat{d} \in \mathbf{R}^{\mathbf{q}}$ are respectively the estimated state vector, the state vector of the observer and the estimated unknown input. $\Phi_{\mathrm{i}}$ are the integral gains matrices. $\mathrm{N}_{\mathrm{i}}, \mathrm{G}_{\mathrm{i}}, \Delta \mathrm{z}_{\mathrm{i}}, \mathrm{L}_{\mathrm{i}}, \mathrm{H}_{\mathrm{i}}, \Phi_{\mathrm{i}}$ and $\mathrm{M}$ are the unknown parameters of the PIMO which we have to design.

Definition 1. System (6) is called a PIMO for system (2) if for arbitrary initial conditions $\mathrm{x}(0)$ and $\mathrm{z}(0)$ and arbitrary input $u(t)$, the following relations hold:

$$
\begin{gathered}
\lim _{\mathrm{x} \rightarrow \infty}(\mathrm{x}(\mathrm{t})-\hat{\mathrm{x}}(\mathrm{t}))=0 \\
\lim _{\mathrm{x} \rightarrow \infty}(\mathrm{d}(\mathrm{t})-\hat{\mathrm{d}}(\mathrm{t}))=0, \quad \forall \mathrm{d}(0)
\end{gathered}
$$

Let the state estimation error $e(t)=x(t)-\hat{x}(t)$; then it follows from (6) and (2) that:

$$
e(t)=\left(I_{n}-M C\right) x(t)-z(t)
$$

Let $\mathrm{U} \in \mathbf{R}^{\mathbf{n x n}}$ a real matrix such that:

$$
\mathrm{UE}=\mathrm{I}_{\mathrm{n}}-\mathrm{MC}
$$

So, the state estimation error becomes:

$$
\mathrm{e}(\mathrm{t})=\operatorname{UEx}(\mathrm{t})-\mathrm{z}(\mathrm{t})
$$

Now, we assume that the bounded unknown inputs are with slow variation, i.e. $\dot{\mathrm{d}}(\mathrm{t}) \simeq 0$.

Then, for $\zeta(t) \simeq \mathrm{d}(\mathrm{t})-\hat{\mathrm{d}}(\mathrm{t})$ the derivative unknown inputs is:

$$
\dot{\zeta}(\mathrm{t}) \simeq-\dot{\hat{\mathrm{d}}}(\mathrm{t})
$$


The dynamic equation of the state estimation error becomes:

$$
\begin{gathered}
\dot{\mathrm{e}}(\mathrm{t})=\mathrm{UE} \dot{\mathrm{x}}(\mathrm{t})-\dot{\mathrm{z}}(\mathrm{t}) \\
\dot{\mathrm{e}}(\mathrm{t})=\sum_{\mathrm{i}=1}^{\mathrm{h}} \mathrm{h}_{\mathrm{i}}(\xi(\mathrm{t}))\left(\mathrm{N}_{\mathrm{i}} \mathrm{e}(\mathrm{t})+\left(\mathrm{UA}_{\mathrm{i}}-\mathrm{L}_{\mathrm{i}} \mathrm{C}-\mathrm{N}_{\mathrm{i}} \mathrm{UE}\right) \mathrm{x}(\mathrm{t})\right. \\
+\left(\mathrm{UB}_{\mathrm{i}}-\mathrm{G}_{\mathrm{i}}\right) \mathrm{u}(\mathrm{t})+\mathrm{U} \Delta \mathrm{x}_{\mathrm{i}}-\Delta \mathrm{z}_{\mathrm{i}} \\
\left.+\left(\mathrm{U}_{\mathrm{i}} \mathrm{R}-\mathrm{H}_{\mathrm{i}}\right) \mathrm{d}(\mathrm{t})+\mathrm{H}_{\mathrm{i}} \zeta(\mathrm{t})\right)
\end{gathered}
$$

If the following conditions are satisfied:

$$
\begin{gathered}
\mathrm{UA}_{\mathrm{i}}=\mathrm{N}_{\mathrm{i}} \mathrm{UE}+\mathrm{L}_{\mathrm{i}} \mathrm{C} \\
\mathrm{G}_{\mathrm{i}}=\mathrm{UB}_{\mathrm{i}} \\
\Delta \mathrm{z}_{\mathrm{i}}=\mathrm{U} \Delta \mathrm{x}_{\mathrm{i}} \\
\mathrm{H}_{\mathrm{i}}=\mathrm{UR}_{\mathrm{i}} \\
\mathrm{I}_{\mathrm{n}}=\mathrm{UE}+\mathrm{MC}
\end{gathered}
$$

and from (6), (11) and (13), the dynamic of the state estimation and the unknown inputs errors become:

$$
\begin{gathered}
\dot{\mathrm{e}}(\mathrm{t})=\sum_{\mathrm{i}=1}^{\mathrm{h}} \mathrm{h}_{\mathrm{i}}(\xi(\mathrm{t}))\left(\mathrm{N}_{\mathrm{i}} \mathrm{e}(\mathrm{t})+\mathrm{H}_{\mathrm{i}} \zeta(\mathrm{t})\right) \\
\dot{\zeta}(\mathrm{t})=\sum_{\mathrm{i}=1}^{\mathrm{h}} \mathrm{h}_{\mathrm{i}}(\xi(\mathrm{t})) \Phi_{\mathrm{i}} \mathrm{C}(\mathrm{x}(\mathrm{t})-\hat{\mathrm{x}}(\mathrm{t})) \\
\dot{\zeta}(\mathrm{t})=-\sum_{\mathrm{i}=1}^{\mathrm{h}} \mathrm{h}_{\mathrm{i}}(\xi(\mathrm{t})) \Phi_{\mathrm{i}} \mathrm{Ce}(\mathrm{t})
\end{gathered}
$$

The equality (19) and (21) can be written as follows:

$$
\left[\begin{array}{c}
\dot{\mathrm{e}}(\mathrm{t}) \\
\dot{\zeta}(\mathrm{t})
\end{array}\right]=\sum_{\mathrm{i}=1}^{\mathrm{h}} \mathrm{h}_{\mathrm{i}}(\xi(\mathrm{t}))\left[\begin{array}{cc}
\mathrm{N}_{\mathrm{i}} & \mathrm{H}_{\mathrm{i}} \\
-\Phi_{\mathrm{i}} \mathrm{C} & 0
\end{array}\right]\left[\begin{array}{c}
\mathrm{e}(\mathrm{t}) \\
\zeta(\mathrm{t})
\end{array}\right]
$$

If the above dynamic equation error (22) is stable, the state estimation will converge asymptotically to the real state.

\subsection{PI Observer Design}

Since $\operatorname{rank}\left[E^{\mathrm{T}} C^{\mathrm{T}}\right]^{\mathrm{T}}$, and from (18) we obtain,

$$
\left[\begin{array}{ll}
U & M
\end{array}\right]\left[\begin{array}{l}
E \\
C
\end{array}\right]=I_{n}
$$

Then, it can directly deduced that:

$$
\left[\begin{array}{ll}
\mathrm{U} & \mathrm{M}
\end{array}\right]=\left[\begin{array}{l}
\mathrm{E} \\
\mathrm{C}
\end{array}\right]^{+}
$$

where the superscript $(+)$ represents the generalized inverse matrix. So, at this step we can get $\mathrm{U}$ and $\mathrm{M} . \mathrm{G}_{\mathrm{i}}, \mathrm{H}_{\mathrm{i}}$ and $\Delta \mathrm{zi}$ will be given respectively from (15), (16) and (17).

By substituting (18) into (14), we obtain:

$$
\begin{aligned}
\mathrm{UA}_{\mathrm{i}} & =\mathrm{N}_{\mathrm{i}}\left(\mathrm{I}_{\mathrm{n}}-\mathrm{MC}\right)+\mathrm{L}_{\mathrm{i}} \mathrm{C} \\
\mathrm{N}_{\mathrm{i}} & =\mathrm{UA}_{\mathrm{i}}-\left(\mathrm{L}_{\mathrm{i}}-\mathrm{N}_{\mathrm{i}} \mathrm{M}\right) \mathrm{C}
\end{aligned}
$$

Let us note

$$
\mathrm{K}_{\mathrm{i}}=\mathrm{L}_{\mathrm{i}}-\mathrm{N}_{\mathrm{i}} \mathrm{M}
$$

then,

$$
\mathrm{N}_{\mathrm{i}}=\mathrm{UA}_{\mathrm{i}}-\mathrm{K}_{\mathrm{i}} \mathrm{C}
$$

Using the expression of $\mathrm{K}_{\mathrm{i}}$,

$$
\mathrm{L}_{\mathrm{i}}=\mathrm{K}_{\mathrm{i}}+\mathrm{N}_{\mathrm{i}} \mathrm{M}
$$

from (28) and (27), the estimated errors (22) can be written as:

$$
\left[\begin{array}{l}
\dot{\mathrm{e}}(\mathrm{t}) \\
\dot{\zeta}(\mathrm{t})
\end{array}\right]=\sum_{\mathrm{i}=1}^{\mathrm{h}} \mathrm{h}_{\mathrm{i}}(\xi(\mathrm{t}))\left(\overline{\mathrm{A}}_{\mathrm{i}}-\overline{\mathrm{K}}_{\mathrm{i}} \overline{\mathrm{C}}\right)\left[\begin{array}{l}
\mathrm{e}(\mathrm{t}) \\
\zeta(\mathrm{t})
\end{array}\right]
$$

the above equation (30) is also equivalent to:

$$
\dot{\mathrm{e}}_{\mathrm{a}}(\mathrm{t})=\sum_{\mathrm{i}=1}^{\mathrm{h}} \mathrm{h}_{\mathrm{i}}(\xi(\mathrm{t}))\left(\overline{\mathrm{A}}_{\mathrm{i}}-\overline{\mathrm{K}}_{\mathrm{i}} \overline{\mathrm{C}}\right) \mathrm{e}_{\mathrm{a}}(\mathrm{t})
$$

where

$$
\begin{gathered}
\overline{\mathrm{A}}_{\mathrm{i}}=\left[\begin{array}{cc}
\mathrm{UA}_{\mathrm{i}} & \mathrm{H}_{\mathrm{i}} \\
0 & 0
\end{array}\right], \overline{\mathrm{K}}_{\mathrm{i}}=\left[\begin{array}{l}
\mathrm{K}_{\mathrm{i}} \\
\Phi_{\mathrm{i}}
\end{array}\right], \overline{\mathrm{C}}=\left[\begin{array}{ll}
\mathrm{C} & 0
\end{array}\right], \mathrm{H}_{\mathrm{i}}=\mathrm{UR}_{\mathrm{i}} \\
\text { and } \mathrm{e}_{\mathrm{a}}(\mathrm{t})=\left[\begin{array}{l}
\mathrm{e}(\mathrm{t}) \\
\zeta(\mathrm{t})
\end{array}\right]
\end{gathered}
$$

The remaining problem is to find the matrices $\overline{\mathrm{K}}_{\mathrm{i}}$ such that the state estimation error converges asymptotically to zero.

\subsection{Existence Conditions}

The PIMO (6) exists if and only if the pair $\left(\overline{\mathrm{A}}_{\mathrm{i}}, \mathrm{C}\right)$ is detectable $\forall i=1, \ldots, h$. The following theorem gives the existence conditions of this PIMO.

Theorem 1.[6] The PIMO (6) for the multi-models descriptor system (2) converge asymptotically to zero, if and only if the following conditions are hold:

$$
\begin{aligned}
& \text { i. } \operatorname{rank}\left[\begin{array}{l}
\mathrm{E} \\
\mathrm{C}
\end{array}\right]=\mathrm{n} \\
& \text { ii. } \operatorname{rank}\left[\begin{array}{cc}
\mathrm{sE}-\mathrm{A}_{\mathrm{i}} & \mathrm{R}_{\mathrm{i}} \\
0 & \mathrm{sI}_{\mathrm{q}} \\
\mathrm{C} & 0
\end{array}\right]=\mathrm{n}+\mathrm{q}, \forall \mathrm{s} \in \mathbb{C e t} \operatorname{Re}(\mathrm{s}) \geq 0
\end{aligned}
$$

So, it remains to determine the gain $\overline{\mathrm{K}}_{\mathrm{i}}$ of the PIMO ensuring the convergence to zeros of the estimation errors. One uses here, the second Lyapunov method.

Theorem 2. The PIMO (6) is asymptotically stable, if there exists a common positive definite matrix $\mathrm{Q}$ an $\mathrm{d}$ matrices $\mathrm{W}_{\mathrm{i}}=\mathrm{QK}_{\mathrm{i}}$ such that:

$$
\overline{\mathrm{A}}_{\mathrm{i}}^{\mathrm{T}} \mathrm{Q}+\mathrm{Q} \overline{\mathrm{A}}_{\mathrm{i}}-\left(\mathrm{W}_{\mathrm{i}} \overline{\mathrm{C}}\right)^{\mathrm{T}}-\left(\mathrm{W}_{\mathrm{i}} \overline{\mathrm{C}}\right)<0, \forall \mathrm{i} \in\{1, \ldots, \mathrm{h}\}
$$

Proof: Consider the Lyapunov function with the following quadratic form: $V(t)=e_{a}^{T}(t) Q e(t)$. The stability condition for the dynamic error yields that the time derivative of the Lyapunov function should be negative definite. Using the equation (31), the function $\dot{V}(t)$ is derived such as:

$$
\begin{gathered}
\dot{\mathrm{V}}(\mathrm{t})=\dot{\mathrm{e}}_{\mathrm{a}}^{\mathrm{T}}(\mathrm{t}) \mathrm{Qe}_{\mathrm{a}}(\mathrm{t})+\mathrm{e}_{\mathrm{a}}^{\mathrm{T}}(\mathrm{t}) \dot{\mathrm{e}}_{\mathrm{a}}(\mathrm{t}) \\
\dot{\mathrm{V}}(\mathrm{t})=\sum_{\mathrm{i}=1}^{\mathrm{h}} \mathrm{h}_{\mathrm{i}}(\xi(\mathrm{t}))\left\{\mathrm{e}_{\mathrm{a}}^{\mathrm{T}}(\mathrm{t})\left(\left(\overline{\mathrm{A}}_{\mathrm{i}}-\overline{\mathrm{K}}_{\mathrm{i}} \mathrm{C}\right)^{\mathrm{T}} \mathrm{Q}+\mathrm{Q}\left(\overline{\mathrm{A}}_{\mathrm{i}}-\overline{\mathrm{K}}_{\mathrm{i}} \mathrm{C}\right)\right) \mathrm{e}_{\mathrm{a}}(\mathrm{t})\right\}
\end{gathered}
$$

The time derivative of the Lyapunov function is then negative definite if the following inequality holds true

$\sum_{\mathrm{i}=1}^{\mathrm{h}} \mathrm{h}_{\mathrm{i}}(\xi(\mathrm{t}))\left\{\mathrm{e}_{\mathrm{a}}^{\mathrm{T}}(\mathrm{t})\left(\left(\overline{\mathrm{A}}_{\mathrm{i}}-\overline{\mathrm{K}}_{\mathrm{i}} \mathrm{C}\right)^{\mathrm{T}} \mathrm{Q}+\mathrm{Q}\left(\overline{\mathrm{A}}_{\mathrm{i}}-\overline{\mathrm{K}}_{\mathrm{i}} \mathrm{C}\right)\right) \mathrm{e}_{\mathrm{a}}(\mathrm{t})\right\}<0$

$\forall \mathrm{h}_{\mathrm{i}}(\xi(\mathrm{t}))$, with $\sum_{\mathrm{i}=1}^{\mathrm{h}} \mathrm{h}_{\mathrm{i}}(\xi(\mathrm{t}))=1, \operatorname{hi}(\xi(\mathrm{t})) \geq 0$ and $\forall \mathrm{e}_{\mathrm{a}}(\mathrm{t}) \neq 0$, then (34) is satisfied if:

$$
\left(\overline{\mathrm{A}}_{\mathrm{i}}-\overline{\mathrm{K}}_{\mathrm{i}} \mathrm{C}\right)^{\mathrm{T}} \mathrm{Q}+\mathrm{Q}\left(\overline{\mathrm{A}}_{\mathrm{i}}-\overline{\mathrm{K}}_{\mathrm{i}} \mathrm{C}\right)<0, \forall \mathrm{i}=1, \ldots, \mathrm{h}
$$

For $\mathrm{W}_{\mathrm{i}}=\mathrm{Q} \overline{\mathrm{K}}_{\mathrm{i}}$, the above inequalities become 


$$
\overline{\mathrm{A}}_{\mathrm{i}}^{\mathrm{T}} \mathrm{Q}+\mathrm{Q} \overline{\mathrm{A}}_{\mathrm{i}}-\left(\mathrm{W}_{\mathrm{i}} \overline{\mathrm{C}}\right)^{\mathrm{T}}-\left(\mathrm{W}_{\mathrm{i}} \overline{\mathrm{C}}\right)<0, \forall \mathrm{i}=1, \ldots, \mathrm{h}
$$

A solution in $\mathrm{Q}$ and $\mathrm{W}_{\mathrm{i}}$ satisfying LMIs (32) can be found. The observers gains can be deduced as: $\overline{\mathrm{K}}_{\mathrm{i}}=\mathrm{Q}^{-1} \mathrm{~W}_{\mathrm{i}}$ Then, the design of PIMO is achieved and their parameters are given by (28), (29), (15), (16) and (24).

To ensure the rate of estimation error convergence, one defines in the left part of the complex plan a bounded area $\mathrm{S}$ with a line of abscissa $(-\alpha)$ where $\alpha \in \mathrm{R}^{+}$.

The LMIs (32) must be replaced by the following LMIs.

$$
\overline{\mathrm{A}}_{\mathrm{i}}^{\mathrm{T}} \mathrm{Q}+\mathrm{Q} \overline{\mathrm{A}}_{\mathrm{i}}-\left(\mathrm{W}_{\mathrm{i}} \overline{\mathrm{C}}\right)^{\mathrm{T}}-\left(\mathrm{W}_{\mathrm{i}} \overline{\mathrm{C}}\right)+2 \alpha \mathrm{Q}<0, \forall \mathrm{i}=1, \ldots, \mathrm{h}(35)
$$

The presented PIMO gives an asymptotic estimation of both states and unknown inputs. It can b e applied to fault diagnosis for descriptor systems. A restrictive condition of such PIMO design is that we have to consider unknown inputs with slow variation, i.e. $\dot{d}(t) \simeq 0$.

\section{Unknown Input Multi-Observer Structure}

The Unknown Inputs Multi-Observer (UIMO) design for descriptor multi-models is addressed in this subsection. Two parts are studied, the first is dedicated to the state estimation, in the second, an applicability of the disturbance estimate is considered. So, taking the descriptor model (2) with a constant matrix disturbance i.e. $\mathrm{R}_{\mathrm{i}}=\mathrm{R}$, the proposed UIMO has the following form:

$$
\left\{\begin{array}{l}
\dot{z}(t)=\sum_{i=1}^{h} h_{i}(\xi(t))\left(N_{i} z(t)+G_{i} u(t)+L_{i} y(t)+\Delta z_{i}\right) \\
\hat{x}(t)=z(t)+M y(t)
\end{array}\right.
$$

Under assumption A1 and A2, and from (2), (10) and (36), the following dynamic estimation error is obtained as:

$$
\begin{aligned}
\dot{e}(t)=\sum_{i=1}^{h} h_{i}(\xi(t))\left(N_{i} e(t)+\left(U A_{i}-L_{i} C-N_{i} U E\right) x(t)\right. \\
+\left(U B_{i}-G_{i}\right) u(t)+U R d(t)+U \Delta x_{i}-\Delta z_{i}
\end{aligned}
$$

If the conditions (14), (15), (16) and (18) are holds and:

$$
\mathrm{UR}=0
$$

the dynamic error equation will be reduced to:

$$
\dot{\mathrm{e}}(\mathrm{t})=\sum_{\mathrm{i}=1}^{\mathrm{h}} \mathrm{h}_{\mathrm{i}}(\xi(\mathrm{t})) \mathrm{N}_{\mathrm{i}} \mathrm{e}(\mathrm{t})
$$

If the above error dynamic equation is stable, the state estimation will converge asymptotically to the real state.

\subsection{UIMO Design}

After checking the convergence conditions (theorem 1), the design of the UIMO (36) consists in finding gains matrices $K_{i}$ such that the equation (39) is stable. By using (27) and (28), the inequalities (32) can be rewritten as:

$$
\left(\mathrm{UA}_{\mathrm{i}}\right)^{\mathrm{T}} \mathrm{Q}+\mathrm{QUA}_{\mathrm{i}}+\left(\mathrm{W}_{\mathrm{i}} \mathrm{C}\right)^{\mathrm{T}}+\left(\mathrm{W}_{\mathrm{i}} \mathrm{C}\right)<0, \forall \mathrm{i}=1, \ldots, \mathrm{h}
$$

A solution in $\mathrm{Q}$ and $\mathrm{W}_{\mathrm{i}}$ satisfying LMIs (40) can be found. The observers gains can be deduced as: $\mathrm{K}_{\mathrm{i}}=\mathrm{Q}^{-1} \mathrm{~W}_{\mathrm{i}}$. Then, the design of UIMO is achieved and their parameters are deduced from the matrices $\mathrm{U}, \mathrm{M}, \mathrm{Q}$ and $\mathrm{W}_{\mathrm{i}}$ as:

$$
\begin{gathered}
\mathrm{K}_{\mathrm{i}}=\mathrm{Q}^{-1} \mathrm{~W}_{\mathrm{i}} \\
\mathrm{N}_{\mathrm{i}}=\mathrm{UA}_{\mathrm{i}}-\mathrm{K}_{\mathrm{i}} \mathrm{C} \\
\mathrm{L}_{\mathrm{i}}=\mathrm{N}_{\mathrm{i}} \mathrm{M}-\mathrm{K}_{\mathrm{i}} \\
\mathrm{G}_{\mathrm{i}}=\mathrm{UB}_{\mathrm{i}} \\
\Delta \mathrm{z}_{\mathrm{i}}=\mathrm{U} \Delta \mathrm{x}_{\mathrm{i}}
\end{gathered}
$$

where

$$
\left[\begin{array}{ll}
\mathrm{U} & \mathrm{M}
\end{array}\right]=\left[\begin{array}{ll}
\mathrm{I}_{\mathrm{n}} & 0
\end{array}\right]\left[\begin{array}{ll}
\mathrm{E} & \mathrm{R} \\
\mathrm{C} & 0
\end{array}\right]^{+}
$$

if the matrix $\left[\begin{array}{ll}E & R \\ C & 0\end{array}\right]$ is a full column $\operatorname{rank}[12]$.

At this step, the UIMO makes it possible to rebuild the state of the system whatever the presence of the unknown inputs; it is based on the methods of decoupling of the unknown inputs with respect to the estimation error. However, the most critical problem into the design of such UIMO is to solve the equation (38). This decoupling problem is restrictive when the disturbances matrices $\mathrm{R}_{\mathrm{i}}$ are different for all the operating point. On the other hand, the PIMO does not decouple the unknown inputs and then its design does not suffer of this problem.

The PIMO design is more easy by considering this problem but the restriction for the PIMO is to consider that disturbances have slow variation i.e. $\dot{d}(t) \simeq 0$. By summarizing these observers design, the design method of the PIMO is less restrictive.

\subsection{Unknown Inputs Estimation}

Under steady state condition, the state estimation error converges to zero, then substituting the true state $\mathrm{x}(\mathrm{t})$ by its estimate $\hat{x}(t)$ and the unknown inputs $d(t)$ by its estimated $\hat{\mathrm{d}}(\mathrm{t})$ in the multi-models (2) and for hypothesis

$$
\begin{aligned}
& \mathrm{R}_{\mathrm{i}}=\mathrm{R} \text {, we obtain: } \\
& \left\{\begin{array}{l}
E \dot{\hat{x}}(\mathrm{t})=\sum_{\mathrm{i}=1}^{\mathrm{h}} \mathrm{h}_{\mathrm{i}}(\xi(\mathrm{t}))\left(\mathrm{A}_{\mathrm{i}} \mathrm{x}(\mathrm{t})+\mathrm{B}_{\mathrm{i}} \mathrm{u}(\mathrm{t})+\mathrm{R} \hat{\mathrm{d}}(\mathrm{t})+\Delta \mathrm{x}_{\mathrm{i}}\right) \\
\hat{\mathrm{y}}(\mathrm{t})=\mathrm{Cx}(\mathrm{t})
\end{array}\right.
\end{aligned}
$$

The unknown inputs can then be calculated in the following way:

$$
\hat{\mathrm{d}}(\mathrm{t})=\mathrm{R}^{+}\left\{\mathrm{E} \dot{\hat{\mathrm{x}}}(\mathrm{t})-\sum_{\mathrm{i}=1}^{\mathrm{h}} \mathrm{h}_{\mathrm{i}}(\xi(\mathrm{t}))\left(\mathrm{A}_{\mathrm{i}} \mathrm{x}(\mathrm{t})+\mathrm{B}_{\mathrm{i}} \mathrm{u}(\mathrm{t})+\Delta \mathrm{x}_{\mathrm{i}}\right)\right\}
$$

The existence of $\hat{d}(t)$ is ensured by condition (5), and $R$ is of full column rank. The construction of the unknown inputs by the UIMO requires an additional procedure which based on the derive function of the signal $\hat{x}(t)$. However the PIMO offers an estimate of the unknown inputs with the estimated state vector. Where, the interest of the PIMO.

\section{Illustrative Example (A Rolling Disc)}

Consider a singular nonlinear system given by the set of differential and algebraic equations (DAE)[16]. The model 
describes a disc rolling on surface without slipping figure 1 . The disc is connected to a fixed wall with a nonlinear spring and a linear damper. The spring has a positive coefficient $\mathrm{k}$. The damping coefficient of the damper is given by a positive parameter $b$. The radius of the disc is $r$, its inertia is given by $\mathrm{J}$ and the mass of the disc is $\mathrm{m}$.

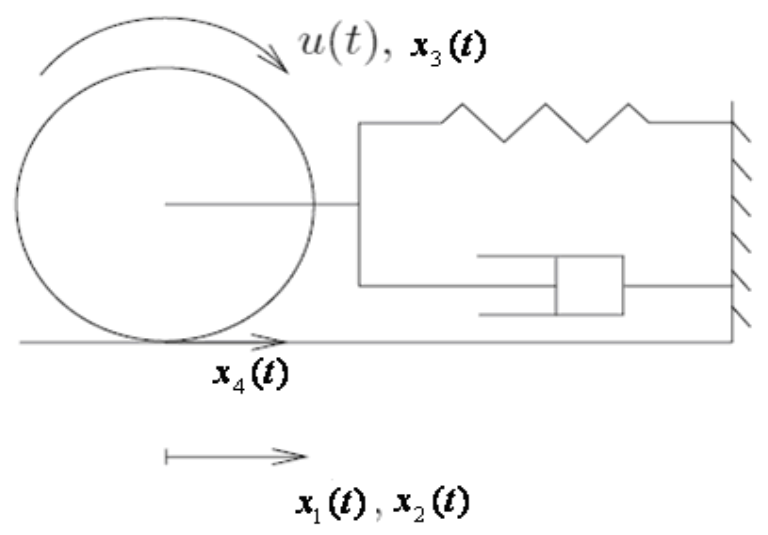

Figure 1. A rolling disc

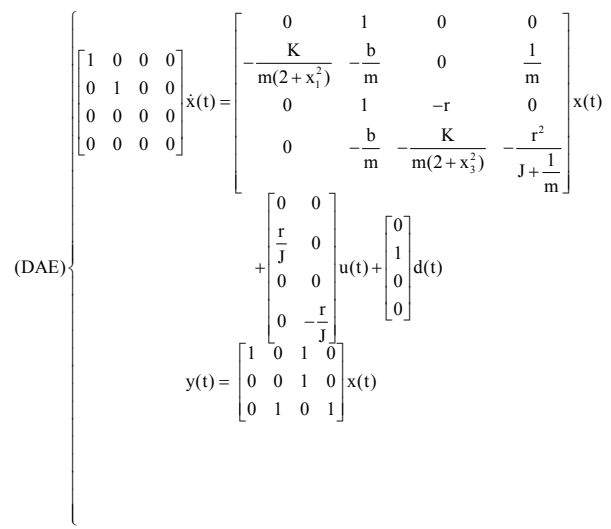

The state vector of this model is given by:

$\mathrm{x} 1(\mathrm{t})$ : The position of the center of this disc $\mathrm{x} 2(\mathrm{t})$ : The translational velocity of the same point.

$\mathrm{x} 3(\mathrm{t})$ : The angular velocity of the disc.

$\mathrm{x} 4(\mathrm{t})$ : The contact force between the disc and the surface.

The control input is denoted $\mathrm{u}(\mathrm{t})$ and is a torque applied at the center of the disc.

Let us: $\mathrm{K}=100 \mathrm{Nm}^{-1}, \mathrm{~b}=30, \mathrm{~m}=40 \mathrm{Kg}, \mathrm{r}=40 \mathrm{~cm}$ and $\mathrm{J}=0.5 \cdot \mathrm{m} \cdot \mathrm{r}^{2}=3.2 \mathrm{Kgm}^{-2}$.

\subsection{Multi-models Representation}

The nonlinear (DAE) can be approximated by three local models interpolated by convex weighting functions as follows:

$$
\left\{\begin{array}{l}
E \dot{x}(t)=\sum_{i=1}^{3} h_{i}(\xi(t))\left(A_{i} x(t)+B_{i} u(t)+R_{i} d(t)+\Delta x_{i}\right) \\
y(t)=C x(t)
\end{array}\right.
$$

The numerical values of those matrices are as follows:

$$
\begin{gathered}
\mathrm{E}=\left[\begin{array}{llll}
1 & 0 & 0 & 0 \\
0 & 1 & 0 & 0 \\
0 & 0 & 0 & 0 \\
0 & 0 & 0 & 0
\end{array}\right], \mathrm{C}=\left[\begin{array}{llll}
1 & 0 & 1 & 0 \\
0 & 0 & 1 & 0 \\
0 & 1 & 0 & 1
\end{array}\right] \\
\mathrm{A}_{1}=\left[\begin{array}{cccc}
0 & 1 & 0 & 0 \\
-2.508 & -0.75 & 0 & 0.025 \\
0 & 1 & -0.4 & 0 \\
0 & -0.75 & -4.1329 & -0.075
\end{array}\right], \\
\mathrm{A}_{2}=\left[\begin{array}{cccc}
0 & 1 & 0 & 0 \\
-3.2532 & -0.75 & 0 & 0.025 \\
0 & 1 & -0.4 & 0 \\
0 & -0.75 & -2.8267 & -0.075
\end{array}\right], \\
\left.\mathrm{A}_{3}=\left[\begin{array}{cccc}
0 \\
0
\end{array}\right], \begin{array}{cccc}
0 \\
0
\end{array}\right] \\
0 \\
0
\end{gathered}
$$

The weighting functions depend on the measurable state $\mathrm{x} 3(\mathrm{t})$ as follows:

$$
\mathrm{h}_{\mathrm{i}}\left(\mathrm{x}_{3}(\mathrm{t})\right)=\frac{\mu_{\mathrm{i}}\left(\mathrm{x}_{3}(\mathrm{t})\right)}{\sum_{\mathrm{i}=1}^{3} \mu_{\mathrm{i}}\left(\mathrm{x}_{3}(\mathrm{t})\right)}
$$

where $\mu_{i}\left(x_{3}(t)\right)$ are defined by:

$$
\begin{aligned}
& \mu_{1}\left(\mathrm{x}_{3}(\mathrm{t})\right)=\exp \left(-1 / 2\left(\frac{\mathrm{x}_{3}+5}{2}\right)^{2}\right) \\
& \mu_{2}\left(\mathrm{x}_{3}(\mathrm{t})\right)=\exp \left(-1 / 2\left(\frac{\mathrm{x}_{3}}{2}\right)^{2}\right) \\
& \mu_{3}\left(\mathrm{x}_{3}(\mathrm{t})\right)=\exp \left(-1 / 2\left(\frac{\mathrm{x}_{3}-5}{2}\right)^{2}\right)
\end{aligned}
$$

For $\begin{cases}u(t)=-t+2 & \text { for } 0 \leq t \leq 2 \\ u(t)=0 & \text { for } t>2\end{cases}$

and $d(t)$ an unknown input applied for $\leq 5 t \leq 10$. The simulation of the nonlinear system and the multi-models 
representation is given by the following figures.

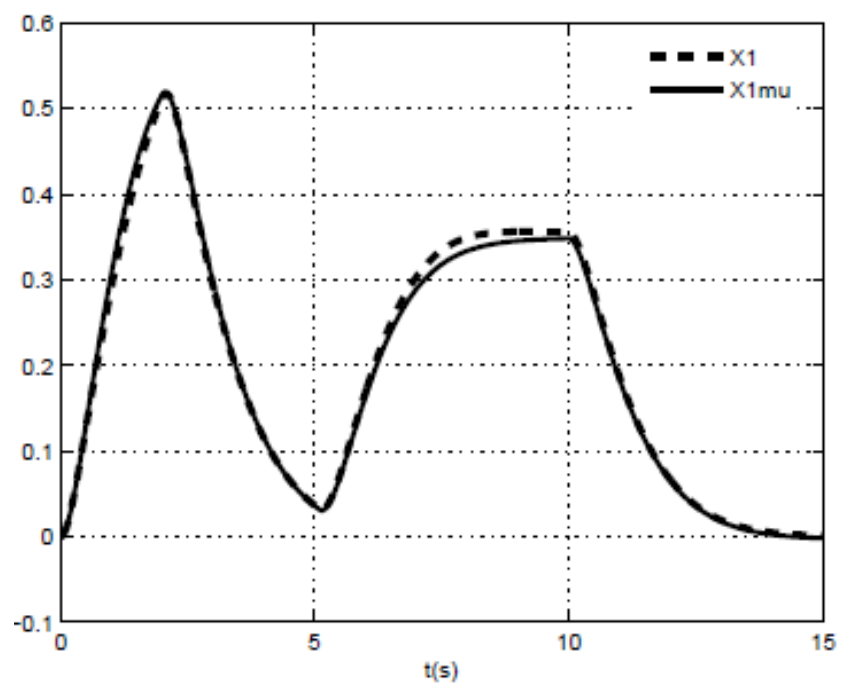

Figure 2. $\mathrm{x}_{1}$ of nonlinear model and $\mathrm{x}_{1}$ of the multi-models

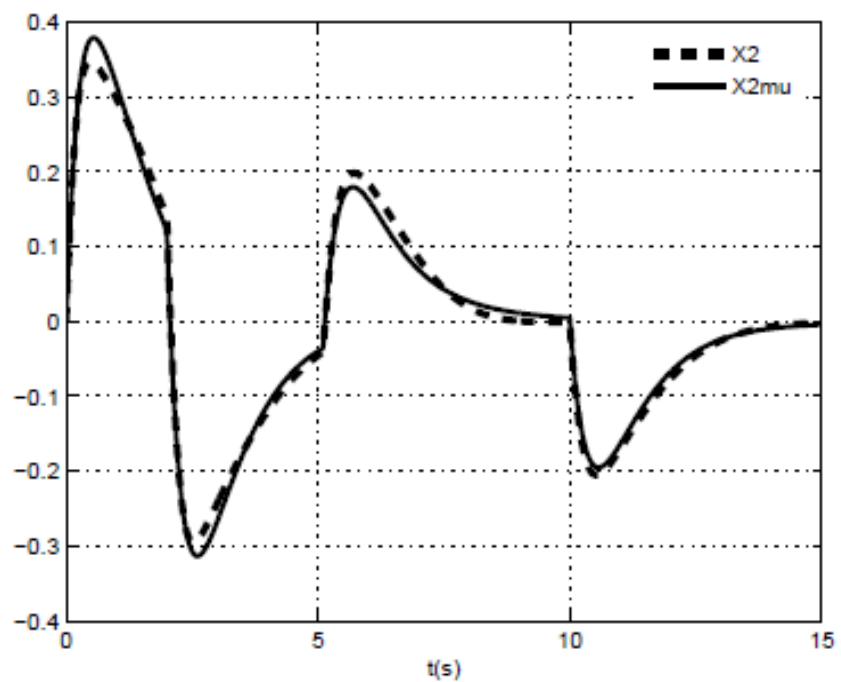

Figure 3. $x_{2}$ of nonlinear model and $x_{2}$ of the multi-models

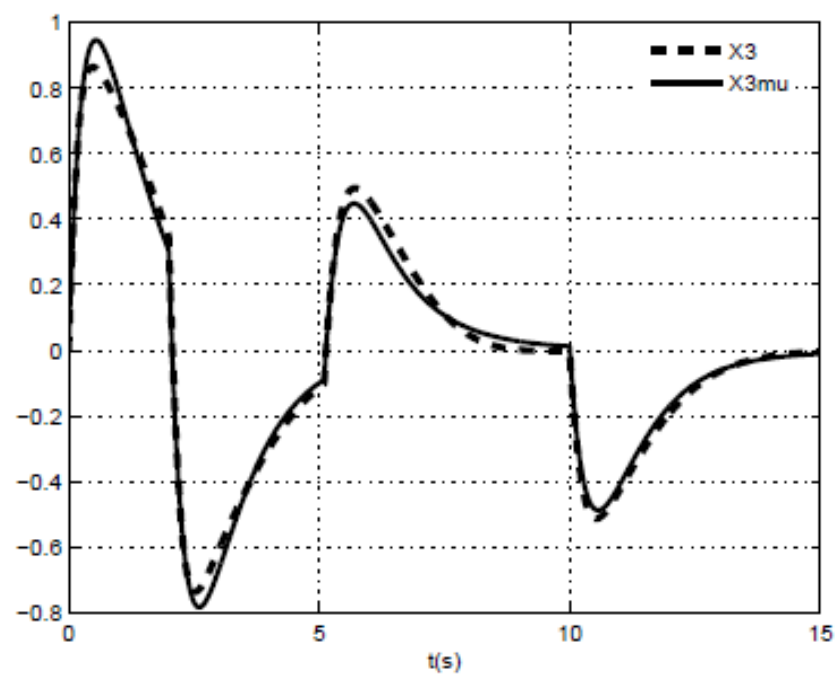

Figure 4. $x_{3}$ of nonlinear model and $x_{3}$ of the multi-models

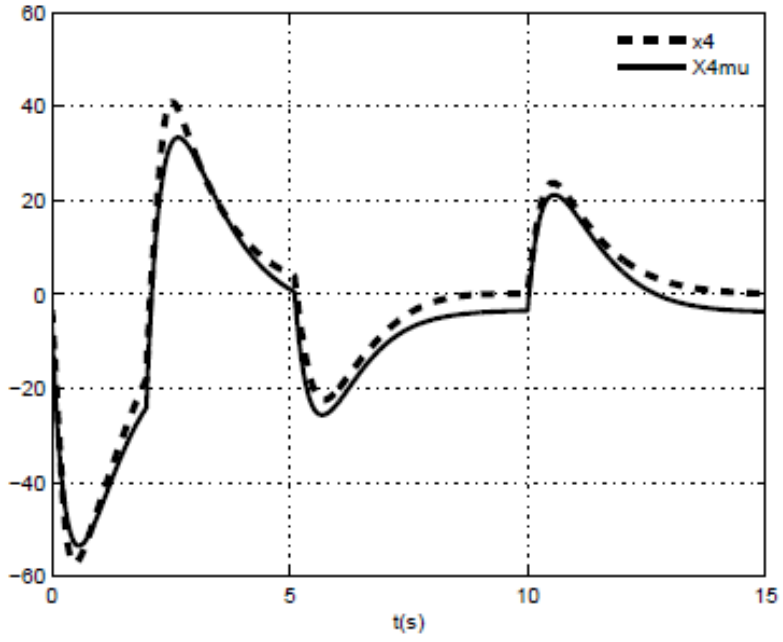

Figure 5. $\mathrm{x}_{4}$ of nonlinear model and $\mathrm{x}_{4}$ of the multi-models

These figures consider the multi-models form with the nonlinear system. They illustrate the superposition of the nonlinear states with those coming from the multi-models representation. We can see that the multi-models well approximate the nonlinear dynamic behavior.

\subsection{State Estimation}

- PI multi-observer matrices: The proportional integral multi-observer is represented by:

$$
\left\{\begin{array}{l}
\dot{\mathrm{z}}(\mathrm{t})=\sum_{\mathrm{i}=1}^{3} \mathrm{~h}_{\mathrm{i}}\left(\mathrm{x}_{3}(\mathrm{t})\right)\left(\mathrm{N}_{\mathrm{i}} \mathrm{z}(\mathrm{t})+\mathrm{G}_{\mathrm{i}} \mathrm{u}(\mathrm{t})+\mathrm{L}_{\mathrm{i}} \mathrm{y}(\mathrm{t})+\mathrm{H}_{\mathrm{i}} \hat{\mathrm{d}}(\mathrm{t})+\Delta \mathrm{z}_{\mathrm{i}}\right) \\
\hat{\mathrm{x}}(\mathrm{t})=\mathrm{z}(\mathrm{t})+\mathrm{My}(\mathrm{t}) \\
\dot{\hat{\mathrm{d}}}(\mathrm{t})=\sum_{\mathrm{i}=1}^{3} \mathrm{~h}_{\mathrm{i}}\left(\mathrm{x}_{3}(\mathrm{t})\right) \Phi_{\mathrm{i}}(\mathrm{y}(\mathrm{t})-\hat{\mathrm{y}}(\mathrm{t}))
\end{array}\right.
$$

The existence of the multi-observer is checked. A solution satisfying the inequality (35) can b e found by using the LMI Toolbox. Then, these inequalities (35) are fulfilled with:

$$
\begin{aligned}
\mathrm{K}_{1} & =\left[\begin{array}{cccc}
-2.5371 & 0.1108 & 3.5 & 0.0288 \\
9.9636 & -3.9838 & 1.71 & -0.2866 \\
-16.5466 & 0.6315 & -0.3311 & 0.1852 \\
-0.1522 & 0.0382 & -0.0093 & 3.5036
\end{array}\right], \\
\mathrm{K}_{2} & =\left[\begin{array}{cccc}
-3.2894 & 0.2548 & 3.5 & 0.0437 \\
26.7464 & 17.5204 & 2.1992 & 1.1789 \\
54.6251 & -8.7911 & -0.2298 & 1.6922 \\
0.5608 & 0.7586 & -0.0048 & 3.5573
\end{array}\right], \\
\mathrm{K}_{3} & =\left[\begin{array}{cccc}
-2.7512 & 0.1429 & 3.5 & 0.0325 \\
14.4807 & 1.7065 & 1.8432 & -0.1654 \\
8.0243 & -1.8632 & -0.3111 & -0.2889 \\
0.0974 & -0.0564 & -0.0085 & 3.4964
\end{array}\right], \\
\Phi_{1} & =\left[\begin{array}{llll}
130.5052 & -40.4398 & 29.0434 & -3.5806
\end{array}\right], \\
\Phi_{2} & =\left[\begin{array}{llll}
168.1872 & 186.1140 & 36.8649 & 8.0523
\end{array}\right], \\
\Phi_{3} & =\left[\begin{array}{llll}
131.1294 & 19.5238 & 31.2183 & -1.5719
\end{array}\right]
\end{aligned}
$$

where $\mathrm{K}_{\mathrm{i}}$ are the proportional gains matrices and $\phi_{\mathrm{i}}$ are the integral gains matrices. The other parameters of the PIMO 
are given by (14) to (14), (24), (28) and (29).

- UIMO matrices: The UIMO (36) is designed by solving the inequalities (40). Then, their obtained gains matrices are:

$$
\begin{aligned}
\mathrm{K}_{1} & =\left[\begin{array}{cccc}
-0.2448 & 0.0320 & -3.5 & 0.0012 \\
-3.2631 & 0.3158 & -0.2312 & 0.0237 \\
0.5922 & 0.7896 & 0.0342 & 0.0592 \\
0 & 0 & 0.0012 & -3.5
\end{array}\right], \\
\mathrm{K}_{2} & =\left[\begin{array}{cccc}
-0.2401 & 0.0488 & -3.5 & 0.0018 \\
-3.1642 & 0.4478 & -0.2233 & 0.0336 \\
0.8395 & 1.1194 & 0.0419 & 0.0840 \\
0 & 0 & 0.0018 & -3.5
\end{array}\right], \\
\mathrm{K}_{3} & =\left[\begin{array}{cccc}
-0.2437 & 0.0364 & -3.5 & 0.0014 \\
-3.2369 & 0.3508 & -0.229 & 0.0263 \\
0.6578 & 0.8771 & 0.0367 & 0.0658 \\
0 & 0 & 0.0014 & -3.5
\end{array}\right],
\end{aligned}
$$

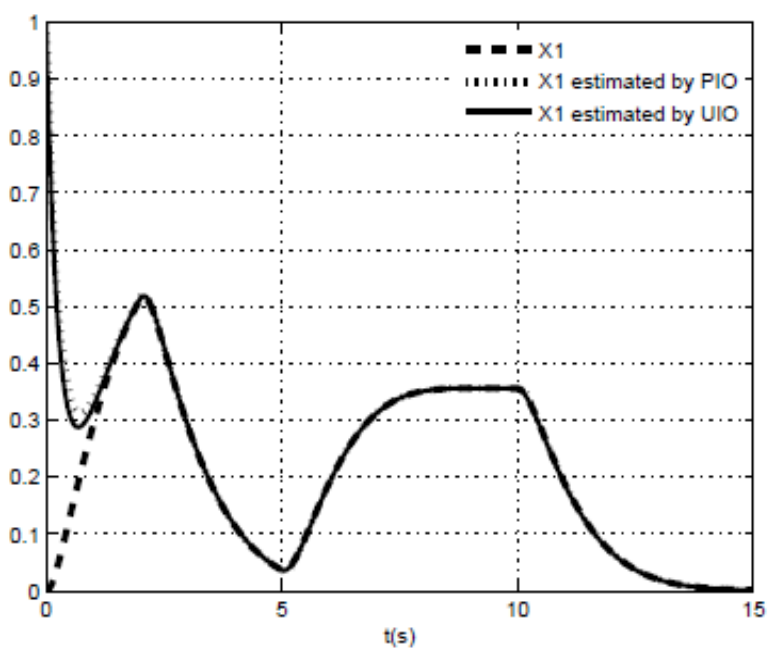

Figure 6. $\mathrm{x}_{1}(\mathrm{t})$ and their estimated by PIMO and UIMO

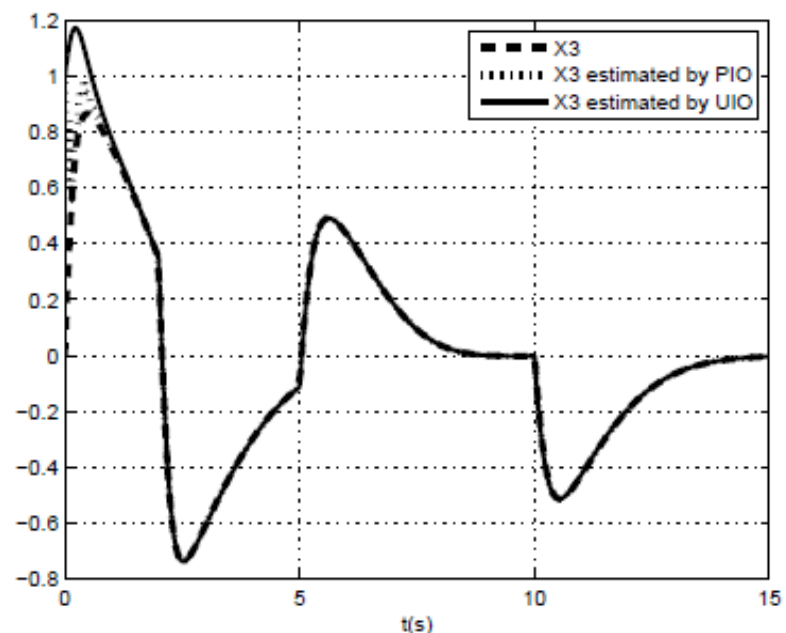

Figure 8. $\mathrm{x}_{3}(\mathrm{t})$ and their estimated by PIMO and UIMO
The other matrices are obtained based on the equations (43) and (46).

Comparison performances between PIMO and UIMO: To evaluate the performances of both PIMO and UIMO in the state and unknown inputs estimation, the following simulation results are given under the same inputs and initial conditions of these observers.

The behavior of the PIMO is shown in the figures (6) to (9). It is observed that for both PI and UI multi-observer, the estimated states can closely track the original states. However, the PIMO rebuilds the state by using the estimate of the unknown inputs, contrary to the UIMO which completely decouples the unknown inputs from the state and thus allows a better estimation.

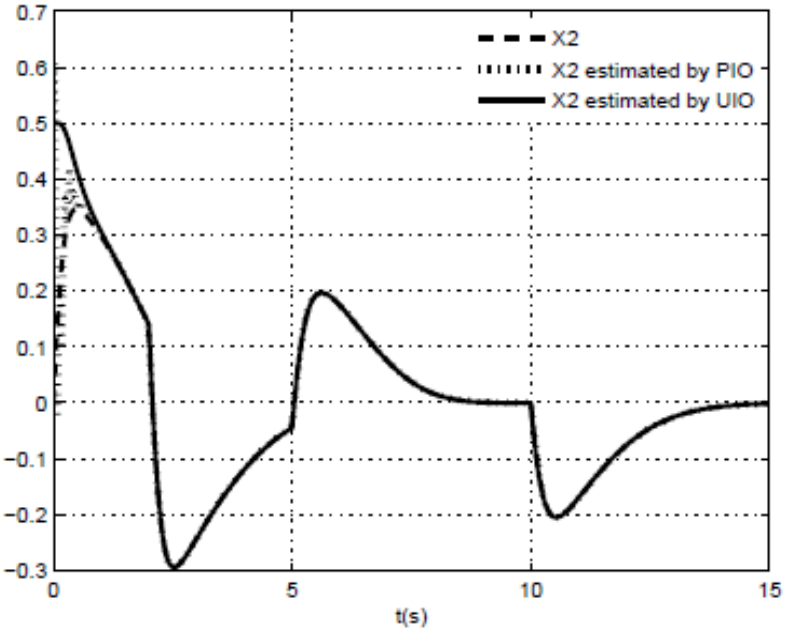

Figure 7. $\mathrm{x}_{2}(\mathrm{t})$ and their estimated by PIMO and UIMO

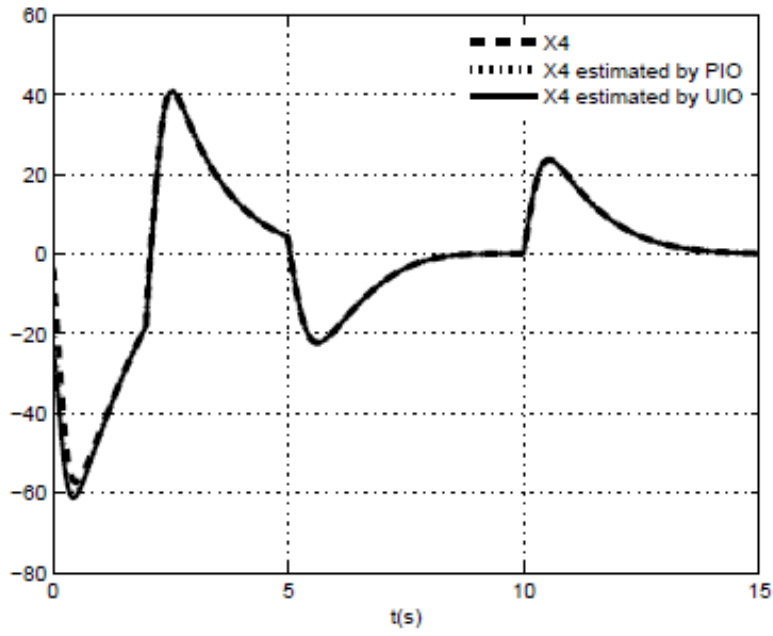

Figure 9. $\mathrm{x}_{4}(\mathrm{t})$ and their estimated by PIMO and UIMO

\subsection{Unknown Inputs Estimation}

Estimated unknown input by booth PIMO and UIMO, is given in the following figure. 


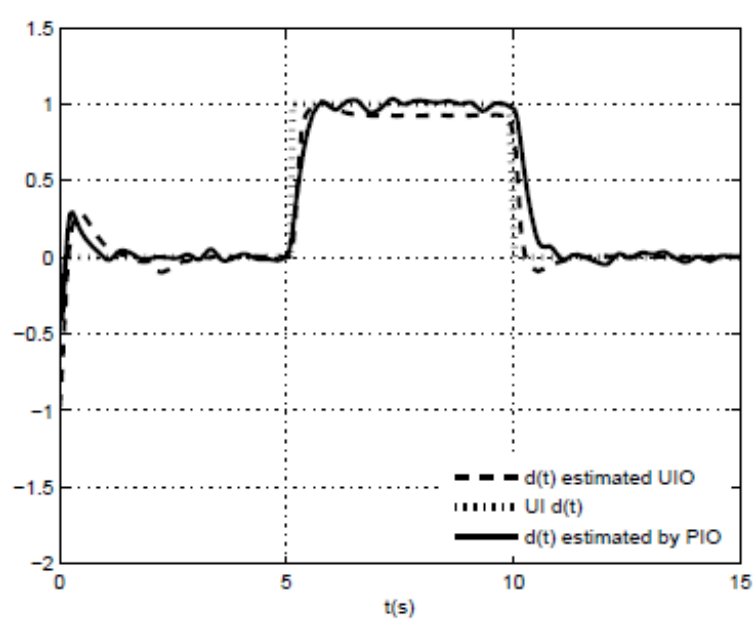

Figure 10. Unknown input $\mathrm{d}(\mathrm{t})$ and their estimated by PIMO and UIMO

The estimation of the unknown inputs (Figure 10) by the PIMO is less better than the one provided by the UIMO.

Indeed, the convergence of the estimation of the unknown inputs by the PIMO is more slowly than the UIMO.

\section{Conclusions}

Performances and design comparison of the state and unknown inputs estimation between Proportional Integral and Unknown Inputs Multi-Observers based on a multimodels approach, for nonlinear descriptor system with unknown inputs has been studied. The nonlinear descriptor system is represented by a set of sub-models where each ones is valid in an operating zone. The PIMO provides a good estimation of the state variables but worse unknown inputs estimation than the UIMO. However, the design of UIMO is more restrictive than the PIMO design. The existence conditions for these both multi-observers and an LMI-based computation have been established. The proposed example illustrates the effectiveness of these proposed multi- observers and allows to compare both state and disturbance estimation.

\section{REFERENCES}

[1] A. G. Wu and G. R. Duan, "Design of PI observers for continuous-time descriptor linear systems", IEEE transactions on systems, man, and cybernetics-part b, vol. 36, no. 6, december 2006.

[2] A. G. Wu and G. R. Duan,"Generalized PI observer design for linear systems", IMA Journal of Mathematical Control and Information, vol. 25, pp 239-250, 2008.

[3] A. Morales, J. A. Ramirez,"A PI observer for a class of nonlinear oscillators", Elsevier Science Physics Letters 297 pp 205-209, 2002.

[4] B. Marx, D. Koenig and J. Ragot,"Design of observers for Takagi-Sugeno descriptor systems with unknown inputs and application to fault diagnosis", IET control theory applica- tions, vol.1, no.5, pp 1487-1495, 2007.

[5] D. Koenig,"An observer design for unknown input nonlinear descriptor systems via convex optimization", IEEE transactions on automatic control, vol. 51, no. 6, pp 1047- 1052, June 2006.

[6] D. Koenig, B. Marx and 0. Sename,’Unknown Inputs Proportional Integral Observers for Descriptor Systems with Multiple Delays and Unknown Inputs", Proceeding of the 2004 American Control Conference Boston. Massachusetts, June 30. July 2, 2004.

[7] D. V. Schrick, "PI-Observer based reconstruction of effect-variables and construction of characteristic curves", Safety Control Engineering, Wuppertal Univ., Germany, vol. 2, pp 937-942, 2004.

[8] H. Hamdi, M. Ro drigues, C. Mechmeche, D. Theilliol and N. BenHadj Braiek," Fault detection and isola-tion in linear parameter-varying descriptor systems via prop ortional integral observer", International jour-nal of adaptive control and signal processing, DOI: 10.1002/acs.1260, 2011.

[9] H. Hamdi, M. Ro drigues, C. Mechemeche, D. Theilliol and N. Benhadj Braiek,"State Estimation for Polytopic LPV Descriptor Systems: Application to Fault Diagnosis" the 7th IFAC Symposium on Fault Detection, Supervision and Safety of Technical Processes, Barcelona, Spain, June 30 - July 3, 2009.

[10] H. Muller, P. C. Muller,'Observer design for decriptor systems", IEEE transactions on automatic control, vol. 44, no. 1, january 1999.

[11] H. S. Kim, T. K. Yeu and S. Kawa ji,"Fault detection in linear descriptor systems via unknown input PI Observer", transactions on control, automation and systems Engineering, Vol. 3, No. 2, June, 2001.

[12] M. Darouach, M. Zasadzinski, and M. Hayar, "Reduced-order observer design for descriptor systems with unknown Inputs", IEEE transactions on automatic control, vol. 41. no. 7, 1996.

[13] M. Rodrigues, D. Theilliol and D. Sauter, "Design of a robust polytopic unknown input observer for FDI: application to nonlinear systems described by a multi-models representation", 44th IEEE Conference on Decision and Control and European Control Conference ECC, Sevilla, Spain, pp 6268-6273, 2005.

[14] M. Rodrigues, M. Adam-Medina, D. Theilliol and D. Sauter,"A fault detection and isolation scheme for industrial systems based on multiple operating models", Control Engineering Practice,vol 16, pp 225-239, 2008.

[15] R. Orjuela, B. Marx, J. Ragot and D. Maquin,"State estimation for non-linear systems using a decoupled multiple mo del", Int. Journal of Model ling, Identification and Control, vol. 4, no. 1, pp 59-67, 2008.

[16] S. Johan and G. Torkel,"Computing the controllability function for nonlinear descriptor systems", Proceedings of the 2006 American Control Conference Minneapolis, Minnesota, USA, June 14-16, 2006.

[17] S. Kaprielian and J. Turi, "An observer for a non linear descriptor system", CDC Tucson, Arizona, pp 975-976, 1992.

[18] T. Taniguchi, K. Tanaka, and H. O. Wang,'Fuzzy descriptor systems and nonlinear model following control", IEEE Transactions on Fuzzy Systems, vol. 8, no. 4, August 2000. 